\title{
Synthesis of $\mathrm{h}$ - and $\alpha-\mathrm{MoO}_{3}$ by Refluxing and Calcination Combination: Phase and Morphology Transformation, Photocatalysis, and Photosensitization
}

\author{
Pannipa Wongkrua, ${ }^{1}$ Titipun Thongtem, ${ }^{1}$ and Somchai Thongtem ${ }^{2,3,4}$ \\ ${ }^{1}$ Department of Chemistry and Center for Innovation in Chemistry, Faculty of Science, Chiang Mai University, \\ Chiang Mai 50200, Thailand \\ ${ }^{2}$ Department of Physics and Materials Science, Faculty of Science, Chiang Mai University, Chiang Mai 50200, Thailand \\ ${ }^{3}$ Materials Science Research Center, Faculty of Science, Chiang Mai University, Chiang Mai 50200, Thailand \\ ${ }^{4}$ Science and Technology Research Institute, Chiang Mai University, Chiang Mai 50200, Thailand
}

Correspondence should be addressed to Titipun Thongtem; ttpthongtem@yahoo.com and Somchai Thongtem; schthongtem@yahoo.com

Received 29 April 2013; Accepted 18 June 2013

Academic Editor: Chunyi Zhi

Copyright (C) 2013 Pannipa Wongkrua et al. This is an open access article distributed under the Creative Commons Attribution License, which permits unrestricted use, distribution, and reproduction in any medium, provided the original work is properly cited.

\begin{abstract}
Hexagonal molybdenum oxide $\left(\mathrm{h}-\mathrm{MoO}_{3}\right)$ nano- and microrods were successfully synthesized by refluxing of $\left(\mathrm{NH}_{4}\right)_{6} \mathrm{Mo}_{7} \mathrm{O}_{24} \cdot 4 \mathrm{H}_{2} \mathrm{O}$ solutions with the $\mathrm{pH} 1$ at $90^{\circ} \mathrm{C}$ for $1,3,5$, and $7 \mathrm{~h}$ and were further transformed into orthorhombic molybdenum oxide $\left(\alpha\right.$ - $\left.\mathrm{MoO}_{3}\right)$ microplates by calcination at $450^{\circ} \mathrm{C}$ for $6 \mathrm{~h}$. These selected products were used to determine the degradation of methylene blue dye under $35 \mathrm{~W}$ xenon lamp for 0-180 min, due to the photocatalysis and photosensitization processes. In this research, catalytic activity of the metastable h- $\mathrm{MoO}_{3}$ has higher efficiency than that of the thermodynamically stable $\alpha-\mathrm{MoO}_{3}$. Their phase and morphology transformation was also explained according to the experimental results.
\end{abstract}

\section{Introduction}

$\mathrm{MoO}_{3}$ is one of the transition metal oxide materials. It has a wide range of applications such as imaging devices, smart windows, electrodes of rechargeable batteries, gas sensors, and supported catalysts [1]. Since $\mathrm{MoO}_{3}$ is a $3.15 \mathrm{eV}$ wide band gap n-type semiconductor, it is well known as one of the most widely used photocatalysts. Its catalytic efficiency has long been known, for example, in alcohol and methane $[2,3]$. Its crystalline structures are known to have three common polymorphs: one thermodynamically stable orthorhombic $\mathrm{MoO}_{3}\left(\alpha-\mathrm{MoO}_{3}\right)$ and two metastable phases hexagonal $\mathrm{MoO}_{3}\left(\mathrm{~h}-\mathrm{MoO}_{3}\right)$ and monoclinic $\mathrm{MoO}_{3}\left(\beta-\mathrm{MoO}_{3}\right)$. The $\mathrm{MoO}_{6}$ octahedrons are the basic building units of all $\mathrm{MoO}_{3}$ structures. For $\alpha-\mathrm{MoO}_{3}$, the $\mathrm{MoO}_{6}$ octahedrons share edges and corners, resulting in zigzag chains and a unique layer structure. But for $\beta-\mathrm{MoO}_{3}$, it has a $\mathrm{ReO}_{3}$-related structure, in which the $\mathrm{MoO}_{6}$ octahedrons share corners to form distorted cubes. The $\mathrm{h}-\mathrm{MoO}_{3}$ is also composed of the same zigzag chains of $\mathrm{MoO}_{6}$ octahedrons connecting through the cispositions $[1,4]$. Moreover, $\mathrm{h}-\mathrm{MoO}_{3}$ exhibits phase stability up to $436^{\circ} \mathrm{C}$ at which the irreversible phase transition occurs to form orthorhombic $\alpha-\mathrm{MoO}_{3}$ [5]. Various molybdenum oxide structures and morphologies have been synthesized by different methods: hexagonal rod-like h- $\mathrm{MoO}_{3}$ by liquid phase deposition [1], nanospheres by ultrasonic-assisted synthesis [3], hexagonal rod-like $\mathrm{h}-\mathrm{MoO}_{3}$ by precipitation $[4,6], \mathrm{MoO}_{3}$ nanorods by ultrasonic synthesis $[5,7], \alpha-$ $\mathrm{MoO}_{3}$ nanobelts by hydrothermal synthesis $[8,9], \mathrm{h}-\mathrm{MoO}_{3}$ rods by solution precipitation and solvothermal treatment [10], $\mathrm{MoO}_{3}$ nanostructures by solution combustion [11], $\alpha$ $\mathrm{MoO}_{3}$ polycrystalline thin films by spray pyrolysis [12], $\mathrm{MoO}_{3}$ nanobelts by hydrothermal method [13, 14], h- $\mathrm{MoO}_{3}$ and $\alpha$ $\mathrm{MoO}_{3}$ nanoparticles by hydrothermal synthesis [15], h- $\mathrm{MoO}_{3}$ 


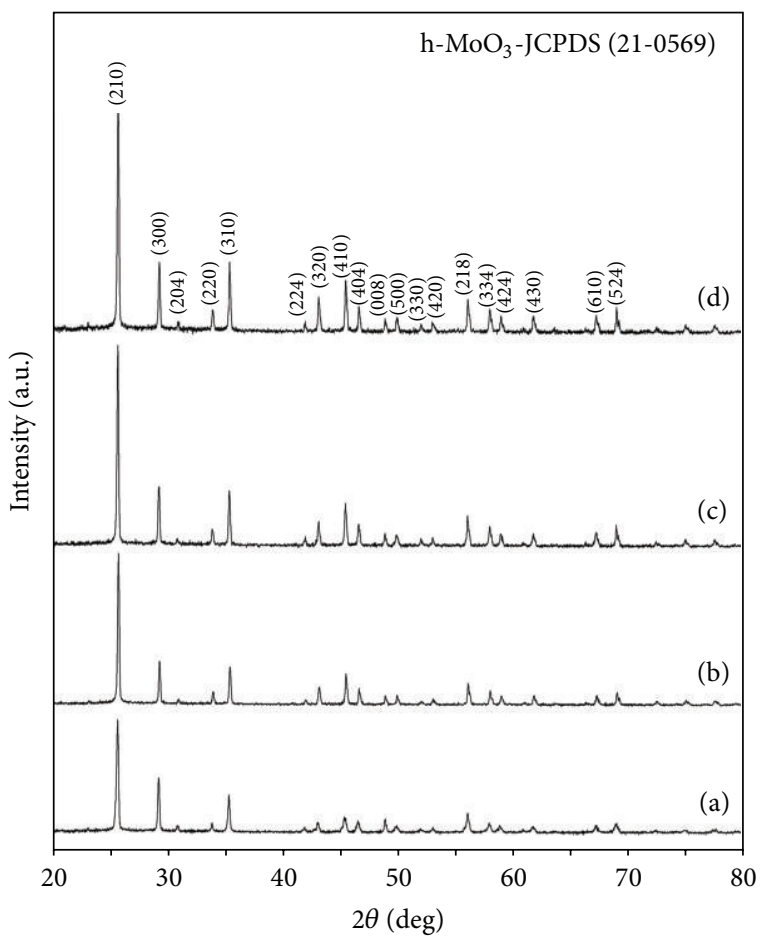

FIGURE 1: XRD patterns of $\mathrm{h}-\mathrm{MoO}_{3}$ synthesized by refluxing method for ((a)-(d)) $1,3,5$, and $7 \mathrm{~h}$, respectively.

nanorods by precipitation $[16,17], \alpha-\mathrm{MoO}_{3}$ microplates by microwave plasma process [18], and $\alpha-\mathrm{MoO}_{3}$ nanocrystals by oil bath heating and sintering combination [19].

In this research, both hexagonal and orthorhombic molybdenum oxide phases were synthesized by refluxing process to form the first and followed by high temperature calcination to form the second. Different phases, phase and morphology transformation (PMT), degradation of methylene blue dye, and mechanisms of photocatalysis and photosensitization are also discussed.

\section{Experimental Procedures}

To synthesize h- $\mathrm{MoO}_{3}$ and $\alpha-\mathrm{MoO}_{3}$ with different morphologies, 0.005 mole ammonium heptamolybdate tetrahydrate $\left(\left(\mathrm{NH}_{4}\right)_{6} \mathrm{Mo}_{7} \mathrm{O}_{24} \cdot 4 \mathrm{H}_{2} \mathrm{O}\right)$ was dissolved in $40 \mathrm{~mL}$ of deionized water with continuous stirring at room temperature for $30 \mathrm{~min}$. Subsequently, $2 \mathrm{M} \mathrm{HNO}_{3}$ was added to the solution until achieving the $\mathrm{pH} 1$ and forming of the clear solution. The solution was processed by a refluxing method at $90^{\circ} \mathrm{C}$ for 1,3 , 5 , and $7 \mathrm{~h}$. In the end, light-blue precipitates were synthesized, separated by filtration, washed, and dried in an electric oven at $80^{\circ} \mathrm{C}$ for $24 \mathrm{~h}$. The products were further calcined at $450^{\circ} \mathrm{C}$ for $6 \mathrm{~h}$ to form powders.

Crystalline phases, morphologies, and vibration modes were characterized by a Philips X'Pert MPD X-ray diffractometer (XRD) at $45 \mathrm{kV}$ and $35 \mathrm{~mA}$ with $\mathrm{Cu} \mathrm{K}_{\alpha}$ radiation in the $2 \theta$ range of $20-80 \mathrm{deg}$ with a scanning rate of $0.04 \mathrm{deg}$ per step, a JEOL JSM-6335F scanning electron microscope (SEM) with an accelerating voltage of $15 \mathrm{kV}$ across the $\mathrm{LaB}_{6}$ cathode,

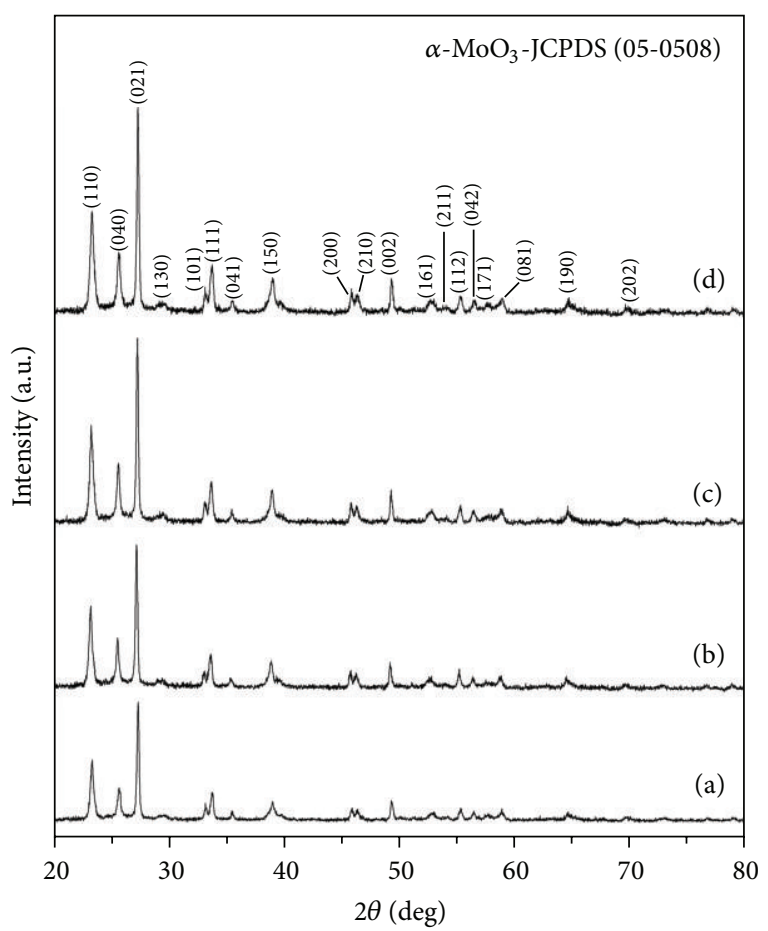

FIgURE 2: XRD patterns of $\alpha-\mathrm{MoO}_{3}$ synthesized by refluxing method for ((a)-(d)) 1, 3, 5, and $7 \mathrm{~h}$ and followed by calcination at $450^{\circ} \mathrm{C}$ for $6 \mathrm{~h}$, respectively.

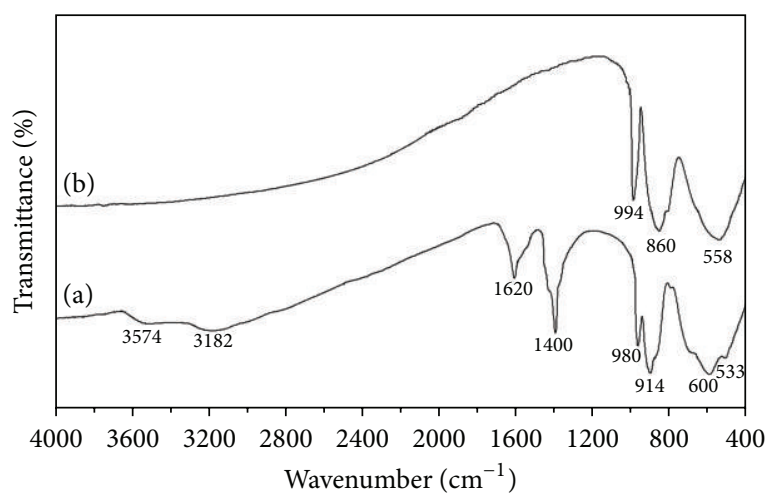

FIgURE 3: FTIR spectra of (a) $\mathrm{h}-\mathrm{MoO}_{3}$ and (b) $\alpha-\mathrm{MoO}_{3}$.

a JEOL JEM-2100F transmission electron microscope (TEM) and selected area electron diffraction (SAED) at $200 \mathrm{kV}$, and a Bruker Tensor 27 Fourier transform infrared (FTIR) spectrometer with $\mathrm{KBr}$ as a diluting agent operated in the range of $4000-400 \mathrm{~cm}^{-1}$ with the resolution of $4 \mathrm{~cm}^{-1}$. In the end, photoluminescence (PL) of the products was analyzed by a LS50B PerkinElmer fluorescence spectrometer using $337 \mathrm{~nm}$ excitation wavelength at room temperature and photoabsorption by a Lambda-25 PerkinElmer UV-visible spectrometer in the wavelength range of $250-800 \mathrm{~nm}$.

The degradation of methylene blue (MB) dye aqueous solutions was investigated. Each $150 \mathrm{mg} \mathrm{MoO}$ was added to a $150 \mathrm{~mL} 1.0 \times 10^{-5} \mathrm{M}$ MB solution, which was stirred for $30 \mathrm{~min}$ in the dark condition to establish an adsorption-desorption 


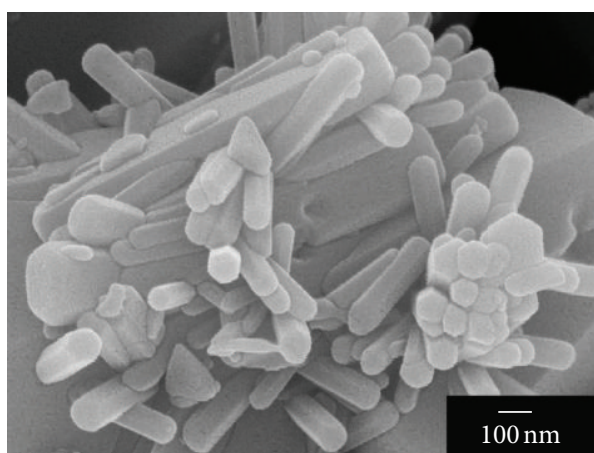

(a)

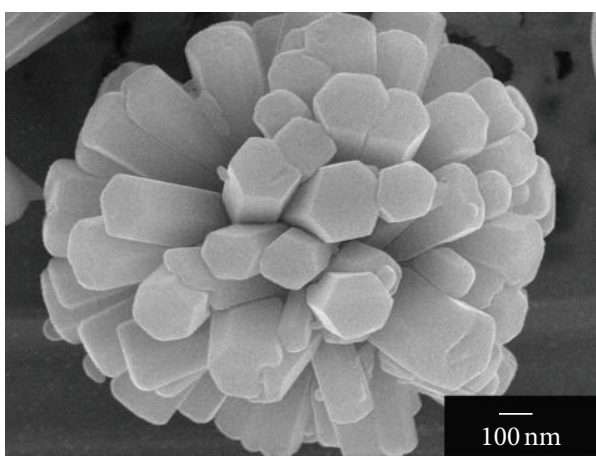

(c)

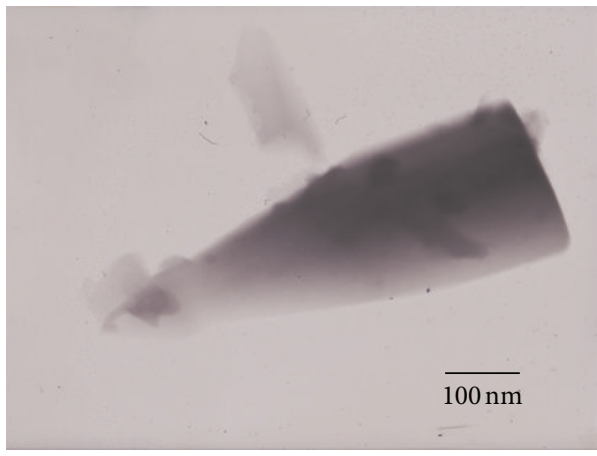

(e)

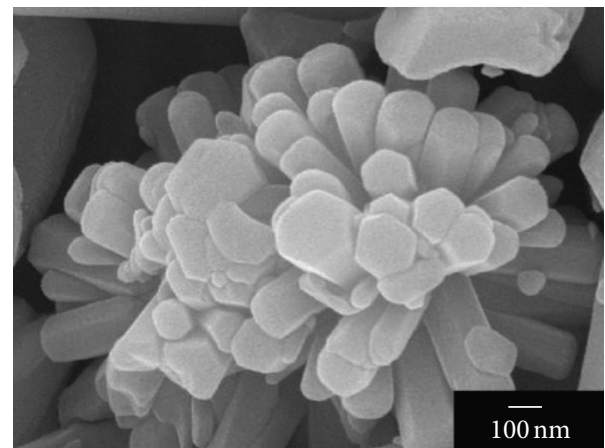

(b)

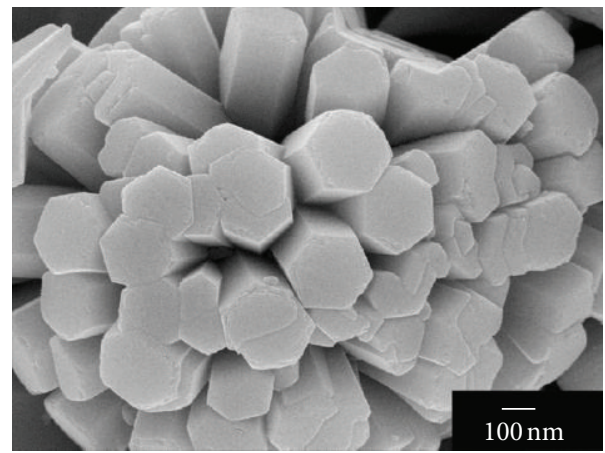

(d)

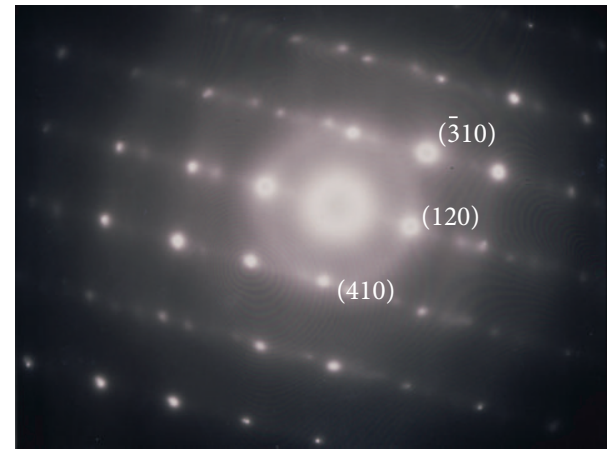

(f)

FIGURE 4: SEM images of $\mathrm{h}-\mathrm{MoO}_{3}$ synthesized by refluxing method for ((a)-(d)) 1, 3, 5, and $7 \mathrm{~h}$, respectively. (e) TEM image and (f) SAED pattern of $\mathrm{h}-\mathrm{MoO}_{3}$ processed for $7 \mathrm{~h}$.

equilibrium. Thus, the MB dye molecules have a chance to adsorb on the $\mathrm{MoO}_{3}$ surfaces. Degradation was initiated by a $35 \mathrm{~W}$ Xe lamp for 0-180 min. The absorbance peak (strongest intensity) at $664 \mathrm{~nm}$ wavelength, determined by UV-visible spectrometer, was assumed to be linearly dependent on the concentration of MB solution. Decolorization efficiency (\%) was calculated by $\left(\left(I_{o}-I\right) / I_{o}\right) \times 100$, where $I_{o}$ and $I$ were the absorbance intensities of the solutions before and after degradation, respectively.

\section{Results and Discussion}

3.1. XRD. XRD patterns of the products synthesized by a refluxing method for $1,3,5$, and $7 \mathrm{~h}$ are shown in Figure 1. All the diffraction peaks can be indexed to be pure hexagonal (h) $\mathrm{MoO}_{3}$ phase (JCPDS no. 21-0569) [20]. Their crystalline degrees were improved by increasing the length of reaction time. Upon calcination of the products at $450^{\circ} \mathrm{C}$ for $6 \mathrm{~h}$ in air, they were transformed into the orthorhombic $(\alpha)$ $\mathrm{MoO}_{3}$ (JCPDS no. 05-0508) [20] (Figure 2) with no impurity detection.

3.2. FTIR. The functional groups of the products with the best crystalline degree were identified by FTIR (Figure 3) over the range of $4000-400 \mathrm{~cm}^{-1}$ wavenumber. For h- $\mathrm{MoO}_{3}$, its spectrum shows peaks at $3574 \mathrm{~cm}^{-1}$ and $1620 \mathrm{~cm}^{-1}$ corresponding to the stretching and bending vibrations of $\mathrm{O}-$ $\mathrm{H}$ bonds of adsorbed water molecules, respectively. Those at $3182 \mathrm{~cm}^{-1}$ and $1400 \mathrm{~cm}^{-1}$ are due to the stretching and bending vibration of $\mathrm{N}-\mathrm{H}$ of $\mathrm{NH}_{4}{ }^{+}$groups, consistent with 


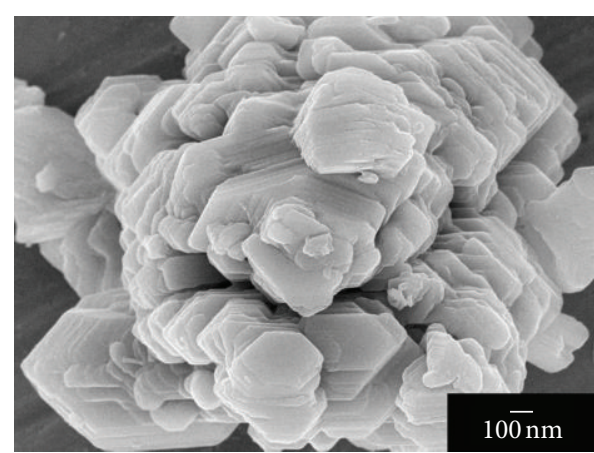

(a)

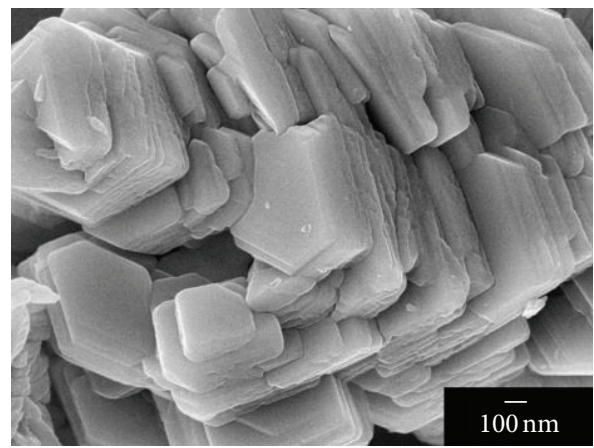

(c)

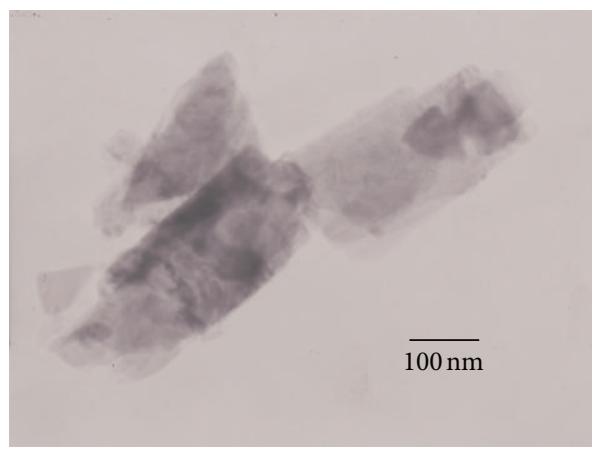

(e)

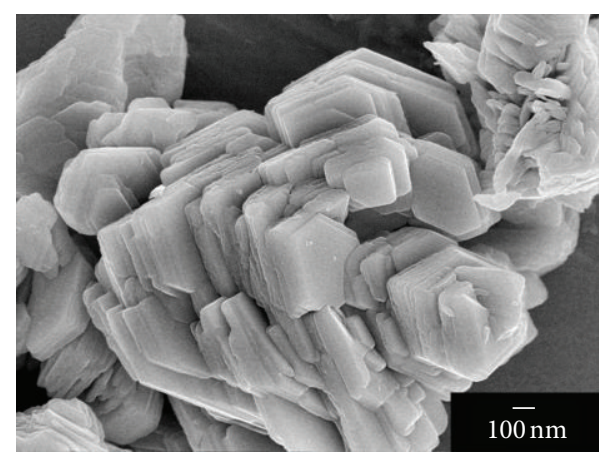

(b)

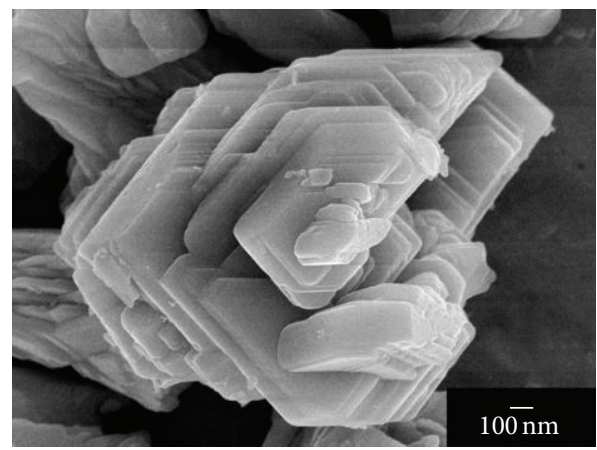

(d)

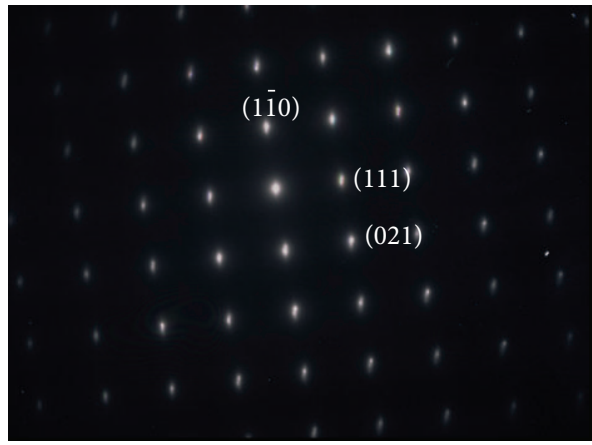

(f)

FIGURE 5: SEM images of $\alpha-\mathrm{MoO}_{3}$ synthesized by refluxing method for ((a)-(d)) 1, 3, 5, and $7 \mathrm{~h}$ and followed by $450^{\circ} \mathrm{C}$ and $6 \mathrm{~h}$ calcination. (e) TEM image and (f) SAED pattern of (d).

the previous report [16]. The $1000-400 \mathrm{~cm}^{-1}$ peaks correspond to the stretching and bending vibrations of metaloxygen characteristic bonds. The peaks at $980 \mathrm{~cm}^{-1}$ and $914 \mathrm{~cm}^{-1}$ are the characteristic of $\mathrm{Mo}=\mathrm{O}$ stretching vibrations, including those between 600 and $500 \mathrm{~cm}^{-1}$ corresponding to the vibration of Mo-O bonds [15, 17]. But for $\alpha-\mathrm{MoO}_{3}$, the spectrum shows three strong peaks: $994 \mathrm{~cm}^{-1}$ attributed to the terminal $\mathrm{M}=\mathrm{O}$ stretching vibration with an indicator of the layered orthorhombic $\mathrm{MoO}_{3}$ phase, $860 \mathrm{~cm}^{-1}$ to the stretching mode of oxygen in Mo-O-Mo bonds, and a broad band at $558 \mathrm{~cm}^{-1}$ to the bending vibration of oxygen atom linked to three metal atoms $[14,15,18]$. No water was detected in this orthorhombic-structured product.
3.3. EM and PMT. Figures 4(a)-4(e) show SEM and TEM images of $\mathrm{h}-\mathrm{MoO}_{3}$ synthesized by refluxing method for different lengths of reaction time. The products shaped like clusters of hexagonal rods with the most complete at $7 \mathrm{~h}$ processing. The rods were $83.82,143.57,182.58$, and $220.84 \mathrm{~nm}$ in diameter for $1,3,5$, and $7 \mathrm{~h}$ processing, respectively. They became enlarged, by transforming from nanosized to microsized rods, with increasing the processing time. In this research, the rods grew out of a center [21], appearing as clusters/flowers of hexagonal rod-like petals and becoming the most complete flowers for $7 \mathrm{~h}$ processing. A SAED pattern of h- $\mathrm{MoO}_{3}$ (Figure 4(f)) reveal as single crystalline h- $\mathrm{MoO}_{3}$. When these products were calcined at $450^{\circ} \mathrm{C}$ for $6 \mathrm{~h}, \mathrm{~h}$ $\mathrm{MoO}_{3}$ structure $(a=b=10.5310 \AA, c=14.8760 \AA$, 


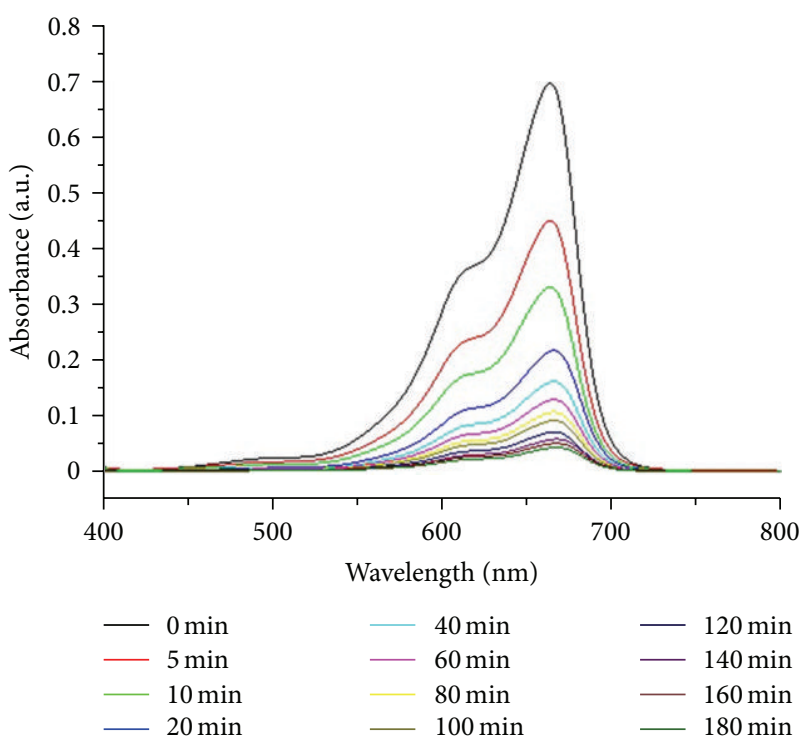

Figure 6: UV-visible spectra of $\mathrm{MB}$ solution containing $\alpha-\mathrm{MoO}_{3}$, synthesized by $90^{\circ} \mathrm{C}$ refluxing for $7 \mathrm{~h}$ in combination with $450^{\circ} \mathrm{C}$ calcination for $6 \mathrm{~h}$ and irradiated by xenon light for different lengths of time.

$\alpha=\beta=90 \mathrm{deg}$, and $\gamma=120 \mathrm{deg}$ ) [20] transformed into $\alpha$ $\mathrm{MoO}_{3}(a=3.9620 \AA, b=13.8580 \AA, c=3.6970 \AA$, and $\alpha=\beta=\gamma=90 \mathrm{deg}$ ) [20]. Concurrently, their morphology transformed from flowers of hexagonal rods (Figures 4(a)$4(\mathrm{e}))$ into assemblies of microplates (Figures 5(a)-5(e)), due to the arrangement of $\mathrm{Mo}$ and $\mathrm{O}$ atoms to achieve the lowest energy. During $450^{\circ} \mathrm{C}$ calcination, flowers of $\mathrm{h}-\mathrm{MoO}_{3}$ rodlike petals were separated into a number of rods. All atoms of these individual rods were at high energy, leading to the vibration and diffusion process. The strength of vibration and diffusion of the solid was controlled by the calcination temperature, bond strength, type of bonds, and others. Thus, the rods were no longerable to retain their original morphologies. When the calcination process was complete at $6 \mathrm{~h}$, the solid was cooled down to room temperature. During cooling, the vibration and diffusion of all atoms slowed down. The atoms returned to their new lattice sites which were at the lowest energy. In the end, the atoms formed a orthorhombic crystalline structure $\left(\alpha-\mathrm{MoO}_{3}\right)$ of which the unit cells arranged themselves into assemblies of microplates. SAED pattern (Figure 5(f)) of the Figure 5(e) product was indexed to be $\alpha-\mathrm{MoO}_{3}$ with the $\left[\begin{array}{lll}-1 & -1 & 2\end{array}\right]$ direction as zone axis.

In this research, $\mathrm{h}-\mathrm{MoO}_{3}$ flowers with 5 and $7 \mathrm{~h}$ refluxing were more perfect than those synthesized by ultrasonic synthesis [7] and chemical precipitation [16, 17], including the corresponding $\alpha-\mathrm{MoO}_{3}$ microplates which were more systematic than those synthesized by microwave plasma [18].

3.4. Photocatalysis, Photosensitization, and Mechanisms. The $\mathrm{MB}$ solution containing metastable h- $\mathrm{MoO}_{3}$ phase with $7 \mathrm{~h}$

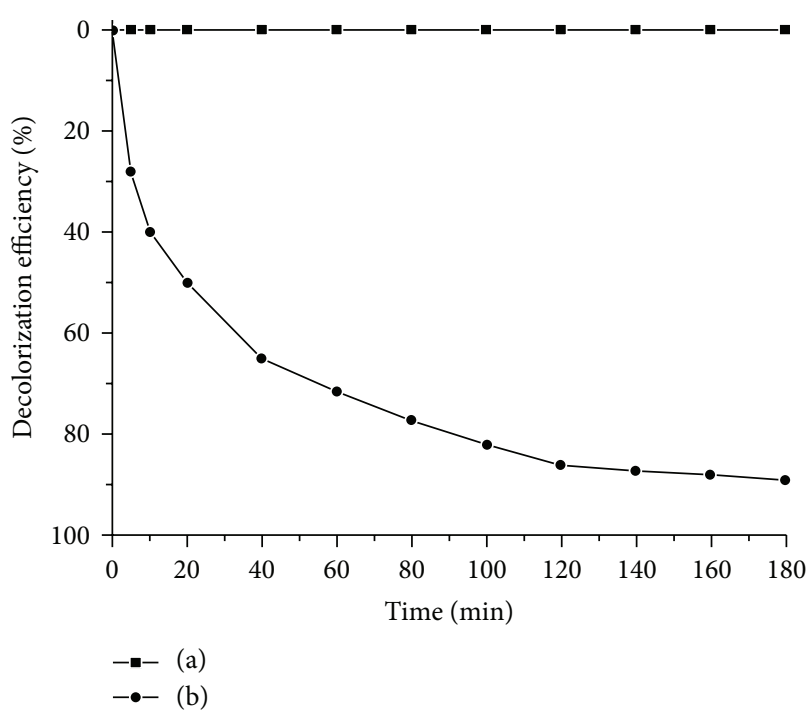

FIGURE 7: Decolorization efficiency of MB: (a) catalyst-free solution and (b) the solution containing $\alpha-\mathrm{MoO}_{3}$ catalyst synthesized by $90^{\circ} \mathrm{C}$ refluxing for $7 \mathrm{~h}$ in combination with $450^{\circ} \mathrm{C}$ and $6 \mathrm{~h}$ calcination and irradiated by xenon light for different lengths of time.

refluxing was studied and became colorless by $30 \mathrm{~min}$ stirring during establishing adsorption-desorption equilibrium. Possibly, the solution containing $\mathrm{h}-\mathrm{MoO}_{3}$ was exposed to UV radiation.

Photocalytic properties of $\alpha-\mathrm{MoO}_{3}$ containing methylene blue $(\mathrm{MB})$ solution irradiated by xenon light for $0-180 \mathrm{~min}$ (Figure 6) were investigated. For cationic MB dye aqueous solution, there are two absorption bands at $293 \mathrm{~nm}$ or $4.23 \mathrm{eV}$ $\left(\pi-\pi^{*}\right)$ and $664 \mathrm{~nm}$ or $1.87 \mathrm{eV}\left(n-\pi^{*}\right)$ [19]. In this research, intensities of absorption peaks at $664 \mathrm{~nm}$ were decreased with the increase in the lengths of irradiation time. Comparing to the catalyst-free solution, the $180 \mathrm{~min}$ degradation of $\mathrm{MB}$ solution (Figure 7) containing $\alpha-\mathrm{MoO}_{3}$ catalyst synthesized by $90^{\circ} \mathrm{C}$ refluxing for $7 \mathrm{~h}$ in combination with $450^{\circ} \mathrm{C}$ calcination for $6 \mathrm{~h}$ was $88 \%$. During photocatalysis or changing of a chemical reaction rate by photons, electrons in valence band of $\alpha-\mathrm{MoO}_{3}$ were excited and transferred to its conduction band under xenon light radiation, leaving holes in valence band behind. Holes combined with $\mathrm{H}_{2} \mathrm{O}$ to form $\bullet \mathrm{H}$ and - $\mathrm{OH}$ radicals. Concurrently, the electrons in conduction band diffused to the adsorbed $\mathrm{O}_{2}$ to form activated $\bullet \mathrm{O}_{2}{ }^{-}$ with subsequent transforming of $\mathrm{H}_{2} \mathrm{O}$ molecules into $\bullet \mathrm{OH}$ radicals. These oxidative species could mineralize $\mathrm{MB}$ dye back into original chemical forms of $\mathrm{CO}_{2}$ and $\mathrm{H}_{2} \mathrm{O}$ creating a cleaner and safer environment [22]. If the processes were not possible, electron-hole pairs would recombine together to generate heat on the materials. Photocatalytic activity was controlled by various factors, including structure, particle size, surface area, crystalline degree, surface-adsorbed water molecules, and hydroxyl groups [23]. The present results show that catalytic activity of the metastable h- $\mathrm{MoO}_{3}$ phase 


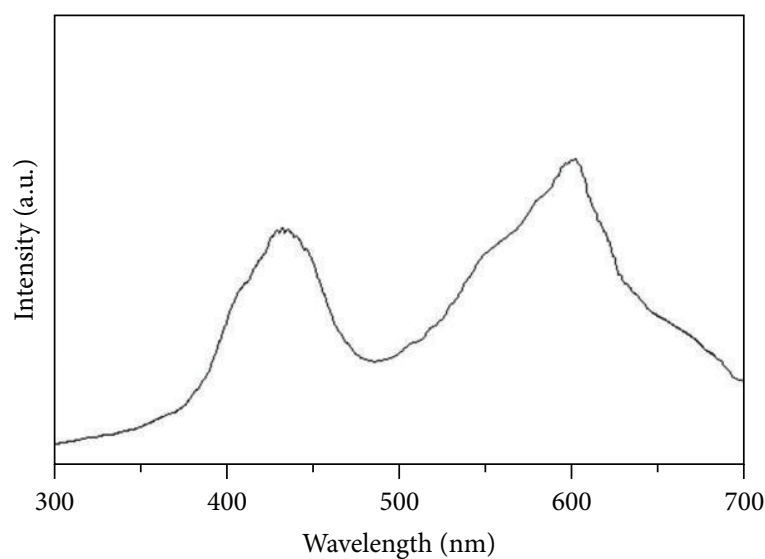

(a)

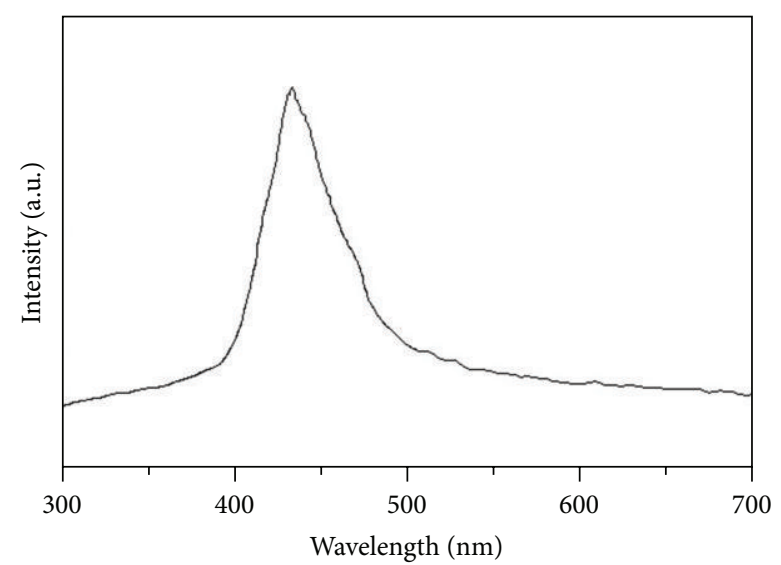

(b)

FIgUre 8: Fluorescence spectra of (a) h- $\mathrm{MoO}_{3}$ and (b) $\alpha-\mathrm{MoO}_{3}$.

has higher efficiency than that of the thermodynamically stable $\alpha-\mathrm{MoO}_{3}$ one.

Photosensitization or the process of initiating reaction by a photonic absorber and transfer of energy to reactants was also possible. Upon irradiation of the solutions by xenon light, the MB dye absorbed photon energy and induced the $\pi-\pi^{*}$ transition (4.23 eV [19]) [14], including $n-\pi^{*}$ transition $(1.87 \mathrm{eV}[19])$. The excited electrons of the MB dye diffused to conduction band (d-orbital) of $\mathrm{MoO}_{3}$ and reacted with adsorbed oxygen to form $\bullet \mathrm{O}_{2}{ }^{-}$oxidants which further mineralized the $\mathrm{MB}$ dye back into $\mathrm{CO}_{2}$ and $\mathrm{H}_{2} \mathrm{O}$. Photolysis or chemical decomposition of dye induced by photon relates to its structural stability [14], which leads to the mineralization process.

In summary, decolorization of $\mathrm{MB}$ dye was able to proceed by the photocatalysis and photosensitization processes or either of the two, influenced by photonic energy, energy gap of $\mathrm{MoO}_{3}$ catalyst, gaps of $n-\pi^{*}$ and $\pi-\pi^{*}$ states of MB dye, and others.

3.5. PL. Figure 8 shows photoluminescence of $\mathrm{h}-\mathrm{MoO}_{3}$ and $\alpha-\mathrm{MoO}_{3}$ excited by $337 \mathrm{~nm}$ wavelength at room temperature. Photons with energy exceeding their energy gaps reflected on the products and generated photoexcited electrons, which are not stable. Thus, they jumped back to a basic state and emitted fluorescence photons with lower energy. They both show strong emission peaks at $436 \mathrm{~nm}$ in accordance with other reports $[9,10,18,19]$, due to the electron-hole recombination. Moreover, $\mathrm{h}-\mathrm{MoO}_{3}$ has another extra peak at $606 \mathrm{~nm}$ specified as the presence of adsorbed oxygen on the material [10].

3.6. UV-Visible Absorption. UV-visible absorption spectroscopy has been used to study photonic properties of materials. Experimentally, the following equation has usually been used to estimate their energy gaps:

$$
\alpha h v=\left(h v-E_{g}\right)^{n}
$$

where $\alpha, h, v$, and $E_{g}$ are the photonic absorbance, the Planck constant, photon frequency, and energy gap, respectively. The parameter $n$ is a constant associated with different types of electronic transition: $n=1 / 2,2,3 / 2$, or 3 for direct allowed, indirect allowed, direct forbidden, and indirect forbidden transitions, respectively, $[9,12,21,24]$. UVvisible spectra (Figure 9) of $\alpha-\mathrm{MoO}_{3}$ and $\mathrm{h}-\mathrm{MoO}_{3}$ show a photonic energy attenuated through the solids. The $(\alpha h \nu)^{2}$ versus $h \nu$ plots were used to estimate energy gaps of $\alpha$ $\mathrm{MoO}_{3}$ and $\mathrm{h}-\mathrm{MoO}_{3}$ to be 3.18 and $3.05 \mathrm{eV}$, respectively. These energy gaps are in accordance with those of $3.35 \mathrm{eV}$ for polycrystalline $\alpha-\mathrm{MoO}_{3}$ thin film [12], $3.75 \mathrm{eV} \alpha-\mathrm{MoO}_{3}$ nanobelts [9], $3.15 \mathrm{eV}$ for $\alpha-\mathrm{MoO}_{3}$ layered structure and $3.01 \mathrm{eV}$ for $\mathrm{h}-\mathrm{MoO}_{3}$ hexagonal rods [15], and $2.99 \mathrm{eV}$ for h$\mathrm{MoO}_{3}$ hexagonal nanorods [16]. Shape, size, size distribution, phase, crystalline degree, and defects can play a role in the energy gaps of materials. Generally, $E_{g}$ becomes wider by using smaller particles but narrower by the presence of defects.

\section{Conclusions}

In this research, $\mathrm{h}-\mathrm{MoO}_{3}$ rods with the shape of flowers were successfully synthesized by refluxing process and further calcination of the flower-like product to form $\alpha$ $\mathrm{MoO}_{3}$ microplates. Their phases, morphologies, and vibration modes were characterized by XRD, SEM, TEM, SAED, and FTIR. Degradation of MB dye under xenon light was proceeding by the photocatalysis and photosensitization processes. Catalytic activity of the metastable h- $\mathrm{MoO}_{3}$ phase has higher efficiency than that of the thermodynamically stable $\alpha-\mathrm{MoO}_{3}$ one. PL emissions were determined to be $436 \mathrm{~nm}$ for $\alpha-\mathrm{MoO}_{3}$ microplates, and 436 and $606 \mathrm{~nm}$ for $\mathrm{h}-\mathrm{MoO}_{3}$ rods, including $E_{g}$ of $3.18 \mathrm{eV}$ for $\alpha-\mathrm{MoO}_{3}$ microplates, and $3.05 \mathrm{eV}$ for $\mathrm{h}-\mathrm{MoO}_{3}$ rods. Their phase and morphology transformation was also explained according to the experimental results. 


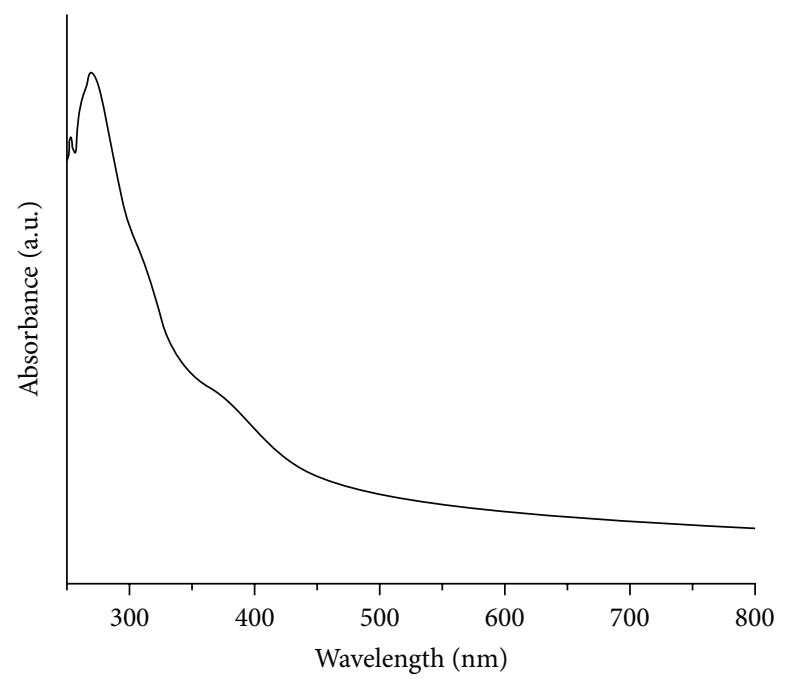

(a)

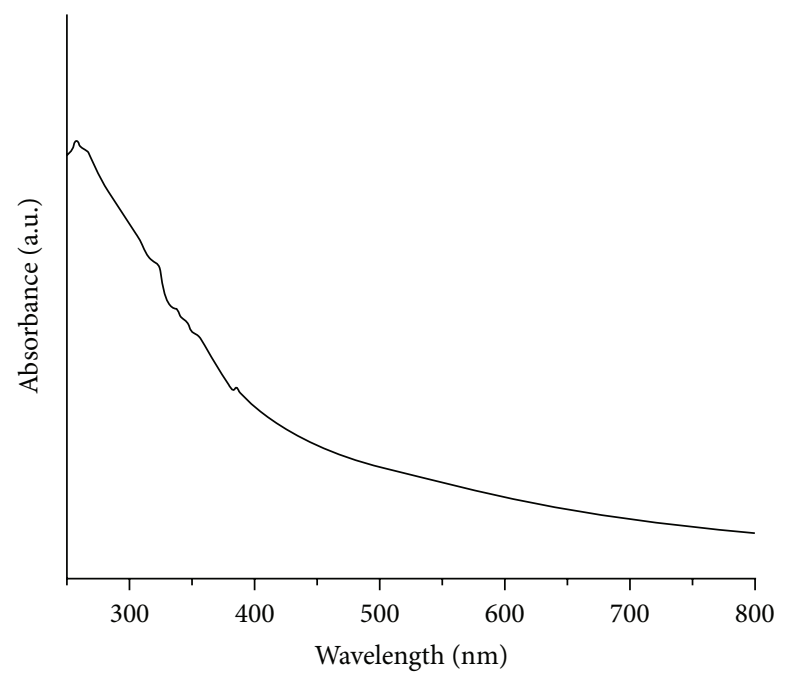

(c)

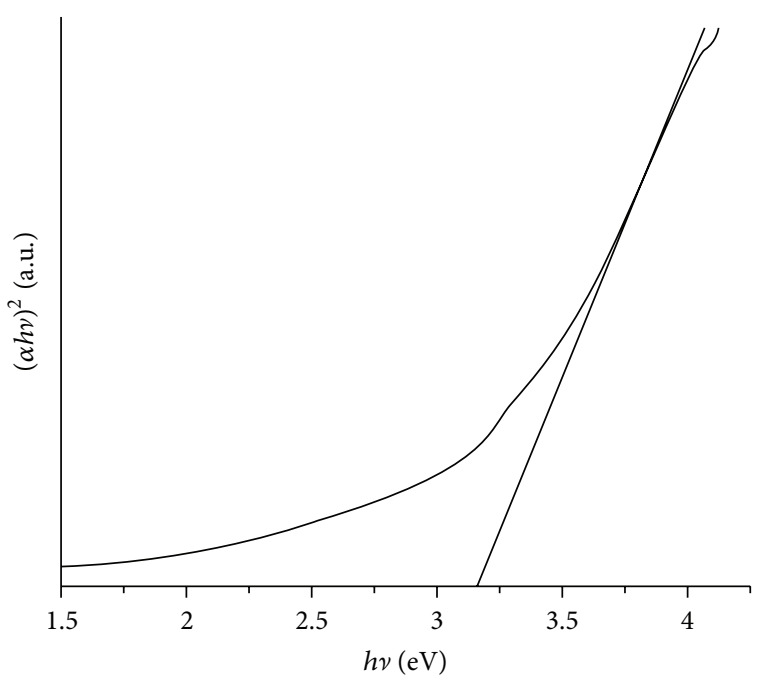

(b)

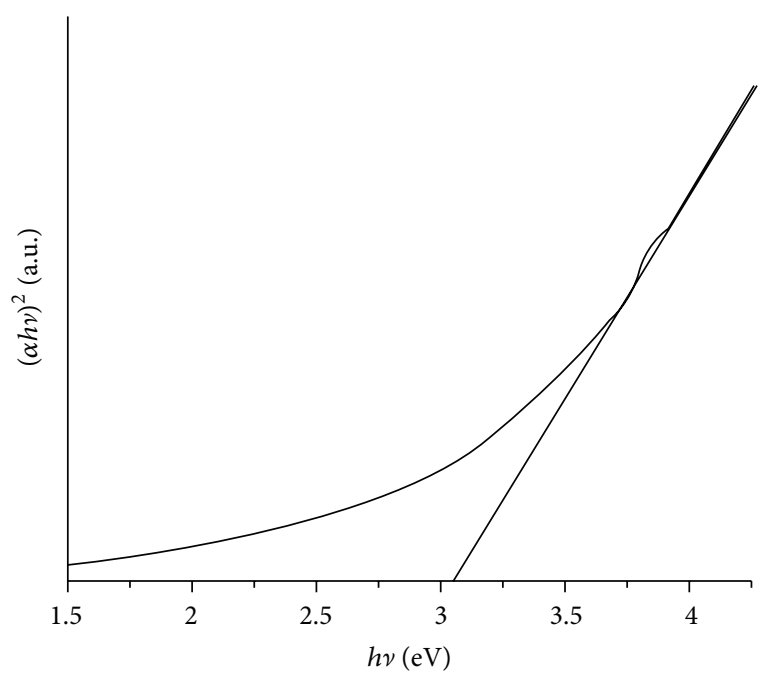

(d)

Figure 9: UV-visible absorbance and the $(\alpha h \nu)^{2}$ versus $h v$ plots of ((a), (b)) $\alpha-\mathrm{MoO}_{3}$ and ((c), (d)) h-MoO .

\section{Acknowledgments}

The authors wish to thank the National Nanotechnology Center (NANOTEC), National Science and Technology Development Agency (NSTDA), for providing financial support through Project P-10-11345, the Thailand's Office of the Higher Education Commission through the National Research University (NRU) Project for Chiang Mai University (CMU), the National Research Council of Thailand (NRCT) through the research project for fiscal year 2556, and the Center for Innovation in Chemistry (PERCH-CIC), including the Graduate School of CMU through a general support.

\section{References}

[1] S. Deki, A. B. Béléké, Y. Kotani, and M. Mizuhata, "Liquid phase deposition synthesis of hexagonal molybdenum trioxide thin films," Journal of Solid State Chemistry, vol. 182, no. 9, pp. 23622367, 2009.

[2] T. He, Y. Ma, Y. Cao, Y. Yin, W. Yang, and J. Yao, "Enhanced visible-light coloration and its mechanism of $\mathrm{MoO}_{3}$ thin films by Au nanoparticles," Applied Surface Science, vol. 180, no. 3-4, pp. 336-340, 2001.

[3] K. Du, W. Fu, R. Wei et al., "Ultrasonic-assisted synthesis of highly dispersed $\mathrm{MoO}_{3}$ nanospheres using 3-mercaptopropyltrimethoxysilane," Ultrasonics Sonochemistry, vol. 15, no. 3, pp. 233-238, 2008.

[4] J. Song, X. Ni, L. Gao, and H. Zheng, "Synthesis of metastable h- $\mathrm{MoO}_{3}$ by simple chemical precipitation," Materials Chemistry and Physics, vol. 102, no. 2-3, pp. 245-248, 2007.

[5] S. Bai, S. Chen, L. Chen et al., "Ultrasonic synthesis of $\mathrm{MoO}_{3}$ nanorods and their gas sensing properties," Sensors and Actuators B, vol. 174, pp. 51-58, 2012.

[6] Z. Wu, D. Wang, X. Liang, and A. Sun, "Ultrasonic-assisted preparation of metastable hexagonal $\mathrm{MoO}_{3}$ nanorods and their 
transformation to microbelts," Ultrasonics Sonochemistry, vol. 18, no. 1, pp. 288-292, 2011.

[7] S. R. Dhage, M. S. Hassan, and O.-B. Yang, "Low temperature fabrication of hexagon shaped $\mathrm{h}-\mathrm{MoO}_{3}$ nanorods and its phase transformation," Materials Chemistry and Physics, vol. 114, no. 2-3, pp. 511-514, 2009.

[8] B. Gao, H. Fan, and X. Zhang, "Hydrothermal synthesis of single crystal $\mathrm{MoO}_{3}$ nanobelts and their electrochemical properties as cathode electrode materials for rechargeable lithium batteries," Journal of Physics and Chemistry of Solids, vol. 73, no. 3, pp. 423429, 2012.

[9] H. Sinaim, D. J. Ham, J. S. Lee, A. Phuruangrat, S. Thongtem, and T. Thongtem, "Free-polymer controlling morphology of $\alpha-\mathrm{MoO}_{3}$ nanobelts by a facile hydrothermal synthesis, their electrochemistry for hydrogen evolution reactions and optical properties," Journal of Alloys and Compounds, vol. 516, pp. 172178, 2012.

[10] J. Song, X. Ni, D. Zhang, and H. Zheng, "Fabrication and photoluminescence properties of hexagonal $\mathrm{MoO}_{3}$ rods," Solid State Sciences, vol. 8, no. 10, pp. 1164-1167, 2006.

[11] D. Parviz, M. Kazemeini, A. M. Rashidi, and K. Jafari Jozani, "Synthesis and characterization of $\mathrm{MoO}_{3}$ nanostructures by solution combustion method employing morphology and size control," Journal of Nanoparticle Research, vol. 12, no. 4, pp. 1509-1521, 2010.

[12] L. Boudaoud, N. Benramdane, R. Desfeux, B. Khelifa, and C. Mathieu, "Structural and optical properties of $\mathrm{MoO}_{3}$ and $\mathrm{V}_{2} \mathrm{O}_{5}$ thin films prepared by Spray Pyrolysis," Catalysis Today, vol. 113, no. 3-4, pp. 230-234, 2006.

[13] H. Sinaim, A. Phuruangrat, S. Thongtem, and T. Thongtem, "Synthesis and characterization of heteronanostructured Ag nanoparticles $/ \mathrm{MoO}_{3}$ nanobelts composites," Materials Chemistry and Physics, vol. 132, no. 2-3, pp. 358-363, 2012.

[14] Y. Chen, C. Lu, L. Xu, Y. Ma, W. Hou, and J. Zhu, "Singlecrystalline orthorhombic molybdenum oxide nanobelts: synthesis and photocatalytic properties," CrystEngComm, vol. 12, no. 11, pp. 3740-3747, 2010.

[15] A. Chithambararaj and A. C. Bose, "Hydrothermal synthesis of hexagonal and orthorhombic $\mathrm{MoO}_{3}$ nanoparticles," Journal of Alloys and Compounds, vol. 509, no. 31, pp. 8105-8110, 2011.

[16] A. Chithambararaj and A. C. Bose, "Investigation on structural, thermal, optical and sensing properties of meta-stable hexagonal $\mathrm{MoO}_{3}$ nanocrystals of one dimensional structure," Beilstein Journal of Nanotechnology, vol. 2, no. 1, pp. 585-592, 2011.

[17] V. V. Atuchin, T. A. Gavrilova, V. G. Kostrovsky, L. D. Pokrovsky, and I. B. Troitskaia, "Morphology and structure of hexagonal $\mathrm{MoO}_{3}$ nanorods," Inorganic Materials, vol. 44, no. 6, pp. 622627,2008 .

[18] A. Klinbumrung, T. Thongtem, and S. Thongtem, "Characterization of orthorhombic $\alpha-\mathrm{MoO}_{3}$ microplates produced by a microwave plasma process," Journal of Nanomaterials, vol. 2012, Article ID 930763, 5 pages, 2012.

[19] L. X. Song, J. Xia, Z. Dang, J. Yang, L. B. Wang, and J. Chen, "Formation, structure and physical properties of a series of $\alpha$ $\mathrm{MoO}_{3}$ nanocrystals: from 3D to $1 \mathrm{D}$ and 2D," CrystEngComm, vol. 14, no. 8, pp. 2675-2682, 2012.

[20] Powder Diffract. File, JCPDS-ICDD, 12 Campus Boulevard, Newtown Square, PA 19073-3273, USA., 2001.

[21] J. Huang, C. Xia, L. Cao, and X. Zeng, "Facile microwave hydrothermal synthesis of zinc oxide one-dimensional nanostructure with three-dimensional morphology," Materials Science and Engineering B, vol. 150, no. 3, pp. 187-193, 2008.
[22] Y. Ku, Y. Huang, and Y. Chou, "Preparation and characterization of $\mathrm{ZnO} / \mathrm{TiO} 2$ for the photocatalytic reduction of $\mathrm{Cr}(\mathrm{VI})$ in aqueous solution," Journal of Molecular Catalysis A, vol. 342343, pp. 18-22, 2011.

[23] M. Vijay, V. Selvarajan, K. P. Sreekumar, J. Yu, S. Liu, and P. V. Ananthapadmanabhan, "Characterization and visible light photocatalytic properties of nanocrystalline $\mathrm{TiO}_{2}$ synthesized by reactive plasma processing," Solar Energy Materials and Solar Cells, vol. 93, no. 9, pp. 1540-1549, 2009.

[24] R. Al-Gaashani, S. Radiman, Y. Al-Douri, N. Tabet, and A. R. Daud, "Investigation of the optical properties of $\mathrm{Mg}(\mathrm{OH})_{2}$ and $\mathrm{MgO}$ nanostructures obtained by microwave-assisted methods," Journal of Alloys and Compounds, vol. 521, pp. 71-76, 2012. 

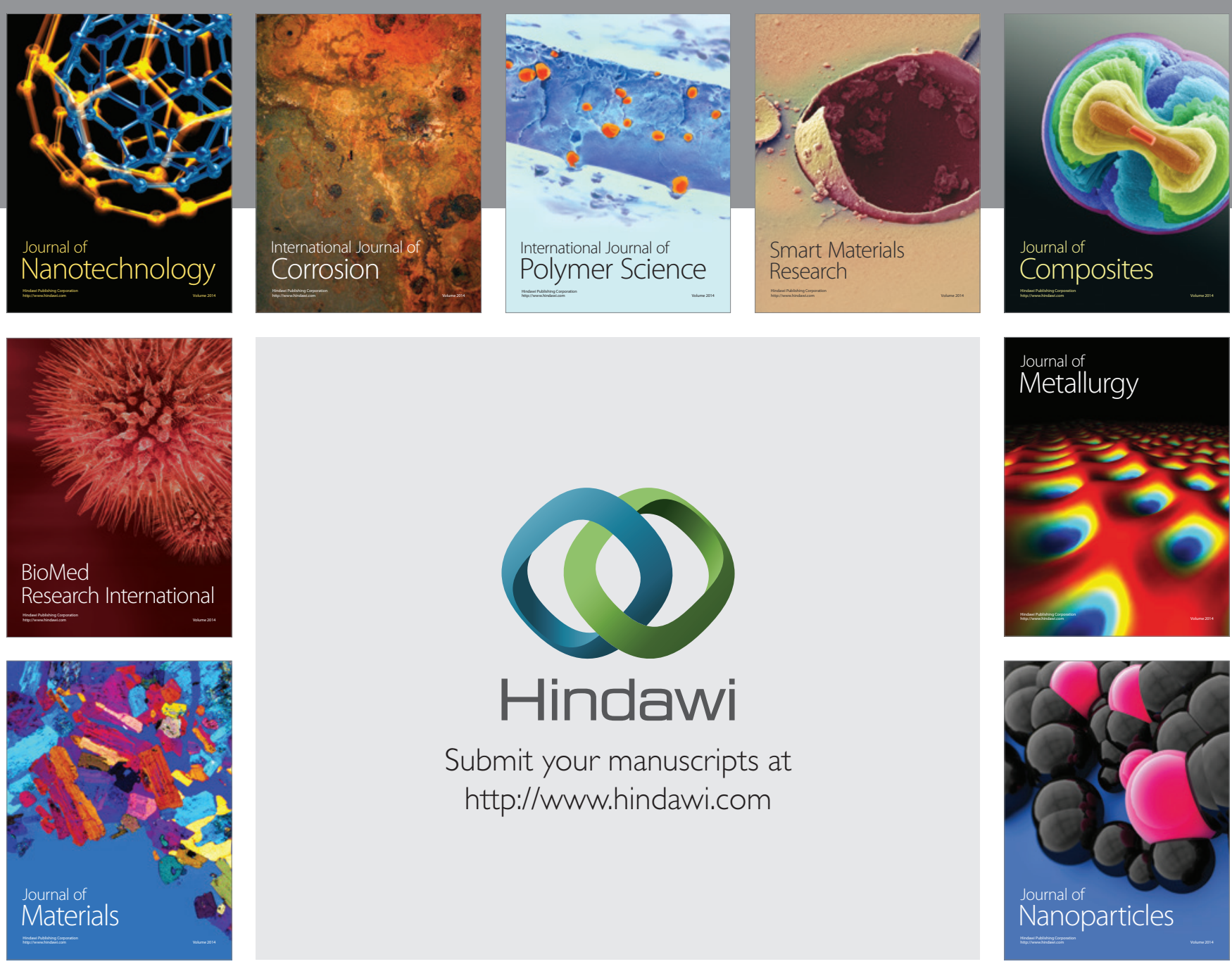

Submit your manuscripts at http://www.hindawi.com
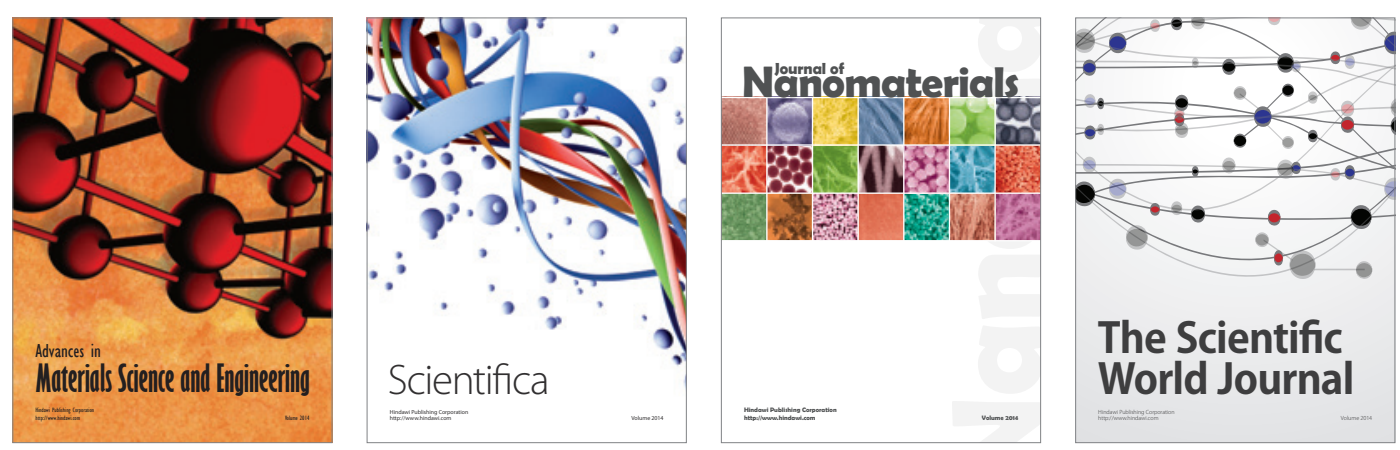

\section{The Scientific World Journal}
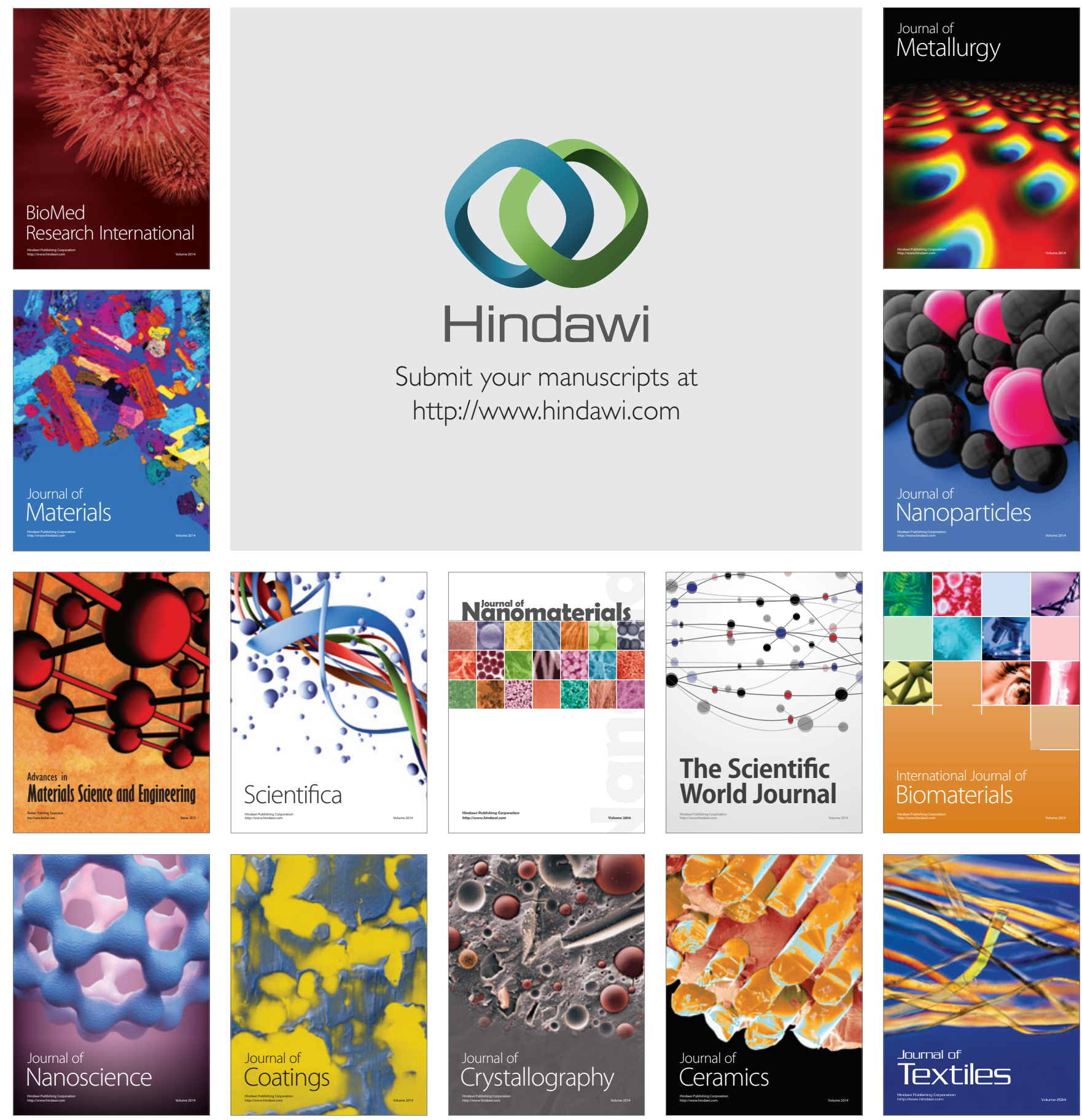